\title{
Supraventricular Tachycardia Induced by Swallowing: A Case Report and Review of the Literature
}

\author{
FRED MORADY, RYSZARD B. KROL, TIMOTHY T. NOSTRANT,* \\ MICHAEL DE BUITLEIR, and WARREN CLINE
}

From the Divisions of Cardiology and Gastroenterology*, Department of Internal Medicine, University of Michigan Medical Center, Ann Arbor, Michigan

\begin{abstract}
MORADY, F., ET AL.: Supraventricular tachycardia induced by swallowing: a case report and review of the literature. A 64-year-old man who complained of palpitations brought on by swallowing was found to have short runs of paroxysmal supraventricular tachycardia (SVT) induced by swallowing. Electrophysiology studies suggested that the SVT was an automatic atrial tachycardia. An esophageal manometric study demonstrated that the tachycardia was coincident with relaxation of the upper esophageal spincter and preceded peristaltic activity in the esophageal body. Atropine and bethanechol did not affect the swallow-induced tachycardia. The patient's symptoms were controlled by verapamil and quinidine. After five months, these medications were discontinued, with no recurrence of symptoms. Based on analysis of ten prior cases and the present case, it appears that swallow-induced SVT generally occurs in men between the ages of 45-75 years who have no evidence of structural heart disease or an esophageal disorder. The SVT is usually either a nonsustained automatic atrial tachycardia or atrial fibrillation. The mechanism is conjectural, but the most likely possibility is a vagally-mediated neural reflex, probably involving a neurotransmitter other than acetylcholine. (PACE, Vol. 10, January-February, 1987)
\end{abstract}

swallowing-induced SVT, atrial tachycardia, esophageal manometric study

\section{Introduction}

Supraventricular tachycardia (SVT) induced by swallowing was reported in the European literature on three occasions between 1926 and $1941 .^{1-3}$ Reports of this unusual entity in the English language literature have been sparse, with ten cases described since 1970, of which only five included a detailed electrophysiologic evaluation. $^{4-13}$

The purpose of the present report is to describe in detail a patient with SVT induced by swallowing and to review the prior reported cases, in an attempt to better characterize this interesting phenomenon.

\footnotetext{
Address for reprints: Fred Morady, M.D., Division of Cardiology, University Hospital, 1500 East Medical Center Drive, UH F2450022, Ann Arbor, MI 48109-0022.
}

Received 6/26/86; accepted 8/4/86.

\section{Case Report}

The patient was a 64-year-old man who began to experience brief episodes of rapid palpitations brought on by swallowing in January 1985 . The palpitations generally lasted only a few seconds and were at times associated with mild lightheadedness. They occurred regardless of whether he swallowed liquids or solids and also occurred during dry swallows. He did not experience palpitations at times other than when he was swallowing. $\mathrm{He}$ had no history of syncope, angina pectoris, myocardial infarction, dysphagia, or dyspepsia. His physician obtained an electrocardiogram and noted brief episodes of a wide complex tachycardia whenever the patient swallowed. Trials of lidocaine, verapamil, quinidine, and procainamide were not effective in suppressing the tachycardia. $\mathrm{He}$ was referred to the University of Michigan Medical Center for evaluation in April 1985.

The physical examination was unremarkable. 
Routine laboratory tests, a chest roentogram, and the 12-lead electrocardiogram were all within normal limits.

An electrophysiology study was performed in the fasting unsedated state after informed consent was obtained. The patient had not taken any medications for 72 hours prior to the study. Three quadripolar electrode catheters were inserted into a femoral vein and positioned in the high lateral right atrium, across the tricuspid valve for recording the His bundle electrogram, and in the apex of the right ventricle.

On multiple occasions the patient was given water to drink and on each occasion swallowing was associated with an episode of tachycardia 39 beats in duration (Figure 1). The tachycardia was initiated by an atrial premature depolarization, which had a coupling interval of $300-450 \mathrm{~ms}$. During the tachycardia, the atrial cycle length varied between 270 and $300 \mathrm{~ms}$. The high right atrial electrogram always preceded the low septal right atrial electrogram. The QRS complexes had a right bundle branch block configuration and were always preceded by a His bundle electrogram, with an HV interval of $45 \mathrm{~ms}$. At times there was atrioventricular (AV) block during the tachycardia. These findings indicated that the tachycardia was atrial in origin and was associated with a functional right bundle branch block. The patient was given several boluses of 2, 5, 10, 20, 30, and $40 \mathrm{ccs}$ of water to swallow, and no relationship was found between the duration of the tachycardia and the size of the bolus.

No tachycardia or reentry beats were induced by incremental right atrial overdrive pacing or by programmed atrial stimulation with one or two extrastimuli during sinus rhythm or during a basic drive cycle length of $500 \mathrm{~ms}$. A functional right bundle branch block occurred during right atrial overdrive pacing at a cycle length of $400 \mathrm{~ms}$. At a
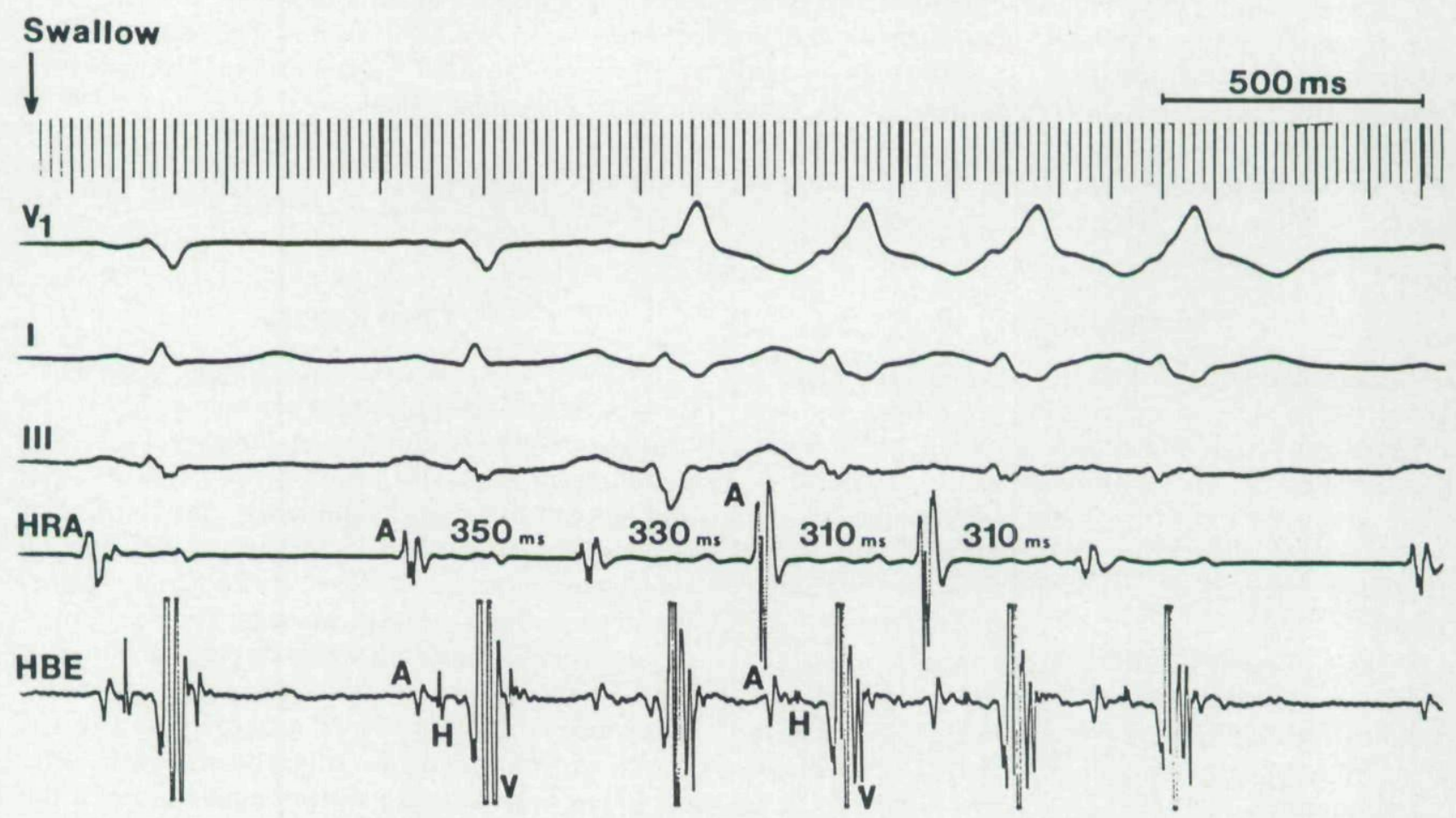

Figure 1. Atrial tachycardia induced by swallowing. The arrow marks the end of a swallow. From top to bottom are leads $V_{1}, I$, III, the high right atrial electrogram (HRA), and the His bundle electrogram (HBE). Two sinus beats are followed by four beats of an atrial tachycardia, cycle length 310-330 ms. During the tachycardia, there is a functional right bundle branch block and an HV interval of $45 \mathrm{~ms}$. (The HV interval of sinus beats was also $45 \mathrm{~ms}$.) Note that during the tachycardia, the HRA precedes the low septal right atrial electrogram (recorded in the HBE.) Abbreviations: A = atrial electrogram; $H=H$ is bundle depolarizations; $V=$ ventricular electrogram. 
basic drive cycle length of $500 \mathrm{~ms}$, the effective refractory period of the right bundle was $390 \mathrm{~ms}$, the functional refractory period of the right atrium was $260 \mathrm{~ms}$, the atrial effective refractory period was $210 \mathrm{~ms}$, and the AV node effective refractory period was less than $260 \mathrm{~ms}$. There was no evidence of an accessory AV connection or dual AV nodal pathways. During incremental right ventricular overdrive pacing, the low septal right atrial electrogram preceded the high right atrial electrogram, and the ventriculoatrial Wenckebach point was at a cycle length of $290 \mathrm{~ms}$.

Carotid sinus massage resulted in neither an abnormal sinus pause nor suppression of the tachycardia in response to swallowing. Intravenous atropine, $2.0 \mathrm{mg}(0.03 \mathrm{mg} / \mathrm{kg})$ resulted in an increase in the sinus rate to 130 beats /minute but had no effect on the duration or rate of the tachycardia induced by swallowing. Intravenous propranolol, $12.5 \mathrm{mg}(0.2 \mathrm{mg} / \mathrm{kg})$ also had no effect on the tachycardia.

An esophageal manometric study was performed 24 hours after the electrophysiology study. The pressures at the upper and lower esophageal sphincters were normal. Peristalsis in the esophageal body was normal, with no evidence of high amplitude or long duration waves and no spontaneous activity or repetitive waves in the basal state. Short runs of tachycardia were consistently provoked by swallowing water and by dry swallows. The onset of the tachycardia was coincident with relaxation of the upper esophageal sphincter and preceded any peristaltic activity in the esophageal body. Bethanechol, $5 \mathrm{mg}(80 \mathrm{mcg} / \mathrm{kg})$, was administered subcutaneously, and the patient was observed for 30 minutes. There was no esophageal dysmotility, no change in esophageal pressure, relaxation length, or peristaltic speed, no change in the tachycardia provoked by swallowing, and no change in the relationship of upper sphincter relaxation to the tachycardia.

Over the next five months, the patient was treated with a combination of verapamil, $320 \mathrm{mg} /$ day, and quinidine sulfate, $1,200 \mathrm{mg} /$ day, with a marked improvement in palpitations. In September, 1985 he discontinued these medications and noted resolution of his symptoms. He has had no recurrence of palpitations. In June 1986, an electrocardiogram demonstrated the absence of tachycardia or premature atrial depolarizations during swallowing.

\section{Literature Review}

Selected features of ten prior cases of swallowinduced SVT and of the present case are summarized in Table I. Each patient had palpitations provoked by swallowing. In three of 11 patients, palpitations also occurred at other times. The mean age of the patients was $57 \pm 11$ years $( \pm$ standard deviation). Two patients had hypertension, and the others did not have clinically apparent structural heart disease or esophageal disorders. Seven of 11 patients had an atrial tachycardia, one had atrial fibrillation, one had an atrial tachycardia which induced AV nodal reentrant tachycradia, one had both an atrial tachycardia and atrial fibrillation, and one had AV reciprocating tachycardia induced by one or two atrial premature depolarizations.

\section{Discussion}

\section{Clinical Features}

Based on the ten prior case reports and the present case report, SVT induced by swallowing can be described as having the following clinical features. Patients with SVT induced by swallowing are usually males between the ages of 45 and 75 years, generally without apparent structural heart disease or esophageal disorders. Palpitations caused by SVT often occur only when swallowing, but some patients also may have palpitations at other times. The palpitations are usually brief, lasting less than 30 seconds, and often less than 5 seconds. In most patients, the palpitations occur with every swallow, regardless of whether the swallow is dry or the patient is swallowing solids or liquids. In a minority of cases, the palpitations may be associated with near syncope or syncope, but most patients do not have severe symptoms in association with the palpitations. In some patients, the palpitations may be a source of anxiety at meal times.

\section{Electrophysiologic Features}

Supraventricular tachycardia provoked by swallowing is most often an atrial tachycardia, and less commonly atrial fibrillation. In no patient who underwent an electrophysiology study was atrial tachycardia inducible by programmed stimulation, suggesting that the mechanism of the atrial tachycardia is most likely automatic instead of reen- 
Table I.

Features of 11 Cases of Supraventricular Tachycardia Induced by Swallowing

\begin{tabular}{|c|c|c|c|c|c|c|c|c|}
\hline \multirow[b]{2}{*}{$\begin{array}{c}\text { Reference } \\
\text { No. }\end{array}$} & \multirow[b]{2}{*}{$\begin{array}{c}\text { Age (yrs)/ } \\
\text { Sex }\end{array}$} & \multicolumn{2}{|c|}{$\begin{array}{c}\text { Tachycardia } \\
\text { Features }\end{array}$} & \multirow[b]{2}{*}{$\begin{array}{l}\text { Rate } \\
\text { (bpm) }\end{array}$} & \multicolumn{2}{|c|}{$\begin{array}{l}\text { Tachycardia } \\
\text { Inducibility }\end{array}$} & \multirow{2}{*}{$\begin{array}{c}\text { Tachycardia } \\
\text { prevented by } \\
\text { atropine }\end{array}$} & \multirow[b]{2}{*}{ Therapy } \\
\hline & & $\begin{array}{c}\text { Mecha- } \\
\text { nism }\end{array}$ & Duration & & PES & $\begin{array}{l}\text { Esophageal } \\
\text { Distension }\end{array}$ & & \\
\hline 4 & $73 / F$ & $\mathrm{AF}$ & $2-3$ mins. & NS & ND & Yes & No & Reserpine \\
\hline 5 & $45 / M$ & Atrial $^{*}$ & $1-8$ beats & 175 & ND & Yes & No & Proc. \\
\hline 6 & $45 / M$ & Atrial $^{\star}$ & $3-6$ beats & $175-124$ & ND & ND & No & Quin. \\
\hline 7 & $52 / \mathrm{M}$ & Atrial & NS & $167-220$ & No & ND & No & Quin. and Prop. \\
\hline 8 & $55 / F$ & Atrial $^{\star}$ & $1-9$ beats & $148-210$ & ND & No & No & Quin. \\
\hline 9 & $46 / M$ & Atrial* $^{\star}$ & $<30$ secs. & 160 & ND & Yes & ND & CEM \\
\hline \multirow[t]{2}{*}{10} & $75 / M$ & Atrial & $5-10$ beats & 162 & No & ND & No & Proc. \\
\hline & & AVNRT† & Sust. & 150 & Yes & ND & No & \\
\hline \multirow[t]{2}{*}{11} & $55 / M$ & Atrial & $<2 \min$ & NS & No & Yes & No & Quin. \& Diso. \\
\hline & & $\mathrm{AF}$ & $<2 \min$ & 170 & No & Yes & No & \\
\hline 12 & $52 / M$ & Atrial & NS & $160-220$ & No & Yes & No & Diso. \\
\hline 13 & $64 / M$ & AVRT†† & Sust. & 188 & Yes & ND & ND & AP Ablation \\
\hline Present & $64 / M$ & Atrial & $3-8$ beats & $188-220$ & No & ND & No & Quin. and Verap. \\
\hline
\end{tabular}

* Presumed mechanisms based on analysis of electrocardiogram

† Always preceded by atrial tachycardia

†† Induced by 1-2 atrial premature depolarizations

Abbreviations: $\mathrm{AF}=$ atrial fibrillation; $\mathrm{AP}=$ accessory pathway; $\mathrm{AVNRT}=$ atrioventricular nodal reentrant tachycardia; $\mathrm{AVRT}=$ atrioventricular reentry tachycardia; $\quad \mathrm{CEM}=$ circular esophageal myotomy; Diso. = disopyramide; $\mathrm{ND}=$ not determined; $\mathrm{NS}=$ not $\mathrm{specified;}$ PES = programmed electrical stimulation; Proc. = procainamide; Prop. = propranolol; Quin. = quinidine; Sust. = sustained; Verap. = verapamil.

trant. The atrial tachycardia is usually $3-10$ beats in duration, with a rate between 150 and 220 beats/minute.

Occasional patients may have typical AV nodal reentrant tachycardia or AV reciprocating tachycardia; however, these tachycardias are induced by either an atrial tachycardia or single or double atrial premature depolarizations provoked by swallowing. Therefore, if the patient has the substrate for a reentrant SVT, the atrial ectopic beats provoked by swallowing may induce reentry if the critical AH or AV interval is attained.

\section{Mechanism}

Two potential mechanisms by which swallowing may provoke atrial ectopy are: mechanical stimulation of the atria by the esophagus; or a neural reflex. Direct mechanical stimulation of the atria can be ruled out for the following reasons: 1) although balloon inflation in the esophagus may induce the tachycardia, the tachycardia is provoked regardless of the location of the balloon within the esophagus; 2) in some cases, balloon inflation in the esophagus at the level of the atria does not provoke tachycardia; 3) the tachycardia is usually provoked even with dry swallowing; 4) as demonstrated in the present case, the tachycardia may occur coincident with relaxation of the upper esophageal sphincter, but before the onset of any peristaltic activity in the esophagus and well before bolus impingement on the atria.

The most likely mechanism by which swallowing may provoke atrial ectopic activity is a neural reflex. Afferent and efferent branches of the vagus nerve are activated during swallowing. ${ }^{14}$ Activation of vagal efferents to the sinus node is presumably the cause of bradycardia provoked by swallowing. ${ }^{15}$ Preferential vagal discharge to the atrial myocardium could conceivably result in atrial ectopic activity without a bradycardia. Several investigators have demonstrated that vagal stimulation or topical or intravenous acetylcholine may induce atrial extrasystoles and atrial fibrillation in animals. ${ }^{16-18}$ Furthermore, carotid sinus massage may provoke atrial fibrillation or atrial 
tachycardia. ${ }^{19,20}$ Therefore, the most likely mechanism of SVT induced by swallowing would appear to be activation of excitatory vagal efferents to the atria.

Of note is that atropine was administered to several patients who had SVT induced by swallowing, and in no instance did atropine suppress the tachycardia. This does not rule out a vagallymediated neural response. Atropine incompletely inhibits the effects of vagal impulses. ${ }^{21}$ For example, the effects of vagal discharge on gut motility are not completely blocked by atropine ${ }^{21}$ This may be because of involvement of a neurohumeral transmitter other than acetylcholine. Consistent with this possibility is the observation in the present case that bethanechol did not provoke the tachycardia.

A neural mechanism involving the sympathetic nervous system has also been suggested to be a possible mechanism of SVT induced by swallowing, because in one case propranolol suppressed the tachycardia. ${ }^{12}$ However, in the present case as well as in four prior cases, propranolol had no effect on the tachycardia. Therefore, although adrenergic activation may be the mechanism of swallow-induced tachycardia in some patients, it is unlikely to play an important role in most patients who have this disorder.

\section{Therapy}

The most effective antiarrhythmic drugs for suppressing swallow-induced SVT have been procainamide, quinidine, and dysopyramide, either alone or in combination with a beta-blocker or a calcium channel blocker. In the one reported case of $\mathrm{AV}$ reciprocating tachycardia induced by swallowing, surgical ablation of the accessory AV connection eliminated the sustained tachycardia but, as would be expected, did not eliminate the atrial extrasystoles induced by swallowing. In one patient, a circular myotomy down to the mucosa of the junction of the middle and lower thirds of the esophagus was performed, in order to interrupt vagal afferents from this portion of the esophagus. This procedure was only partially effective, perhaps because vagal afferents from the upper portion of the esophagus were not interrupted.

Of note is that the patient in the present report had a spontaneous remission of swallow-induced tachycardia six months after its initial onset. The explanation for this spontaneous remission is unclear.

\section{Conclusion}

In conclusion, SVT induced by swallowing is usually a nonsustained automatic atrial tachycardia or atrial fibrillation. Although the mechanism by which swallowing provokes the tachycardia is unclear, the most likely possibility is a vagallymediated neural mechanism, probably involving a neurotransmitter other than acetylcholine.

Acknowledgement: The authors thank Lisa Hackbarth for her excellent secretarial assistance.

\section{References}

1. Sakai D, Mori F. Uber einen Fall von sog "Schlucktachycardie.” Z Gesamte Exp Med 1926; 50:106.

2. Gallavardin L, Froment R. Tachycardie paroxystique de deglutition (avec accidents syncopaux). Lyon Med 1930; 145:456.

3. Clerc A. A propos de la tachycardie de deglutition. Arch Mal Coeur 1941; 34:73.

4. Cohen L, Larson DW, Strandjord N. Swallowinginduced atrial fibrillation. Circulation 1970; 42 (Suppl II):III-45.

5. Bajaj SC, Ragaza EP, Silva $\mathrm{H}$, et al. Deglutition tachycardia. Gastroenterology 1971; 62:632.

6. Lindsay AE. Tachycardia caused by swallowing: Mechanisms and treatment. Am Heart J 1973; 85: 679.

7. Engel TR, LaPorte SM, Meister SG, et al. Case studies: Tachycardia upon swallowing. Evidence

for a left atrial automatic focus. J Electrocardiology 1976; 9:69.

8. Mirvis DM, Bandura JP, Brody DA. Symptomatic swallowing-induced paroxysmal supraventricular tachycardia. Am J Cardiol 1977; 39:741.

9. Kalloor GJ, Singh SP, Collis JL. Cardiac arrhythmias on swallowing. Am Heart J 1977; 93:235.

10. Schroeder DP, Wooley CF, Leier CV. An electrophysiologic study of swallowing-induced tachycardia. Chest 1978; 74:314.

11. Suarez LD, Chiozza MA, Foye R, et al. Swallowingdependent atrial tachyarrhythmias: Their mechanism. J Electrocardiology 1980; 13:301.

12. Bexton RS, Nathan AW, Hellestrand KJ, et al. Paroxysmal atrial tachycardia provoked by swallowing. Br Med J 1981; 282:952.

13. Yeh SJ, Fu M, Lin FC, et al. Paroxysmal supraven- 
tricular tachycardia initiated by a swallowing-induced premature atrial beat. J Electrocardiology 1986; 19:193.

14. Davenport HW. Physiology of the Digestive Tract. Chicago, Year Book Medical Publishers, Inc., Third Edition, 1971, pp. 13-27.

15. Kopald HH, Roth, HP, Fleshler B, et al. Vagovagal syncope: Report of a case associated with diffuse esophageal spasm. N Engl J Med 1964; 271:1238.

16. Scherf D, Chick FB. Abnormal cardiac rhythms caused by acetylcholine. Circulation 1951; 3:764.

17. West TC, Turner L, Loomis TA. Effects of acetylcholine as mechanical and electrical properties of isolated rabbit auricles. J Pharmacol Exp Ther 1954; 3:475.
18. Loomis TA, Krop S. Auricular fibrillation induced and maintained in animals by acetylcholine or vagal stimulation. Circ Res 1955; 3:390.

19. Blumenfeld S, Schaeffeler KT, Zullo RJ. An unusual response to carotid sinus pressure. Am Heart J 1951; 41:319.

20. Scherf D, Cohen J, Rafailzadeh M. Excitatory effects of carotid sinus pressure. Enhancement of ectopic impulse formation and of impulse conduction. Am J Cardiol 1966; 17:240.

21. Innes IR, Nickerson M. Atropine, scopolamine, and related antimuscarinic drugs. In Goodman LS, Gilman A. (Eds.): The Pharmacological Basis of Therapeutics. Fifth Edition, New York, MacMillan Publishing Co. Inc., 1975, pp. 514-532. 
Copyright of Pacing \& Clinical Electrophysiology is the property of Blackwell Publishing Limited and its content may not be copied or emailed to multiple sites or posted to a listserv without the copyright holder's express written permission. However, users may print, download, or email articles for individual use. 